\title{
PHYLOGENETIC ANALYSIS OF Sphaerirostris picae (ACANTHOCEPHALA: CENTRORHYNCHIDAE) BASED ON LARGE AND SMALL SUBUNIT RIBOSOMAL DNA GENE
}

\author{
RADWAN N.A. \\ Department of Zoology, Faculty of Science, University of Tanta, Tanta, Egypt. \\ *Corresponding Author: Email-nahla_ahmad_mohamed@yahoo.com
}

Received: December 10, 2012; Accepted: December 18, 2012

\begin{abstract}
The purpose of the present study was to add new $18 \mathrm{~S}$ and 28S DNA gene sequences data to Sphaerirostris picae (Rudolphi, 1819) Golvan, 1960 and analyze the generated sequences to define the taxonomic placement of genus Sphaerirostris and providing a better resolution inside the Palaeacanthocephala. Two regions: $18 \mathrm{~S}$ and $28 \mathrm{~S}$ of nuclear ribosomal DNA of S. picae were amplified using polymerase chain reaction and sequenced following the instructions of GATC German company facility. Mealign module in the DNAStar Lasergene V7 was used to design a forward and reverse primer of 28S DNA gene. 18S and 28S DNA gene sequences of S. picae were aligned with sequences for both genes of Palacanthocephalans retrieved from GenBank. Results were analyzed using distance matrix methods UPGMA. The resulting phylogenetic trees suggest a paraphyletic arrangement of the two Palaeacanthocephala orders; Echinorhynchida and Polymorphida depending on the placement of the three echinorhynchids, Transvena, Rhadinorhynchus and Gorgorhynchoides in the polymorphid clade. The present study is the first to generate gene sequences of genus Sphaerirostris and discuss its relationships within Palaeacanthocephala. Further comprehensive studies should be done for other species of genus Sphaerirostris and family Centrorhynchidae as all based on molecular phylogenetic analysis to solve their taxonomic overlapping.
\end{abstract}

Keywords- Sphaerirostris picae, Acanthocephala, Ribosomal DNA, Degenerate primer, Phylogenetic analysis

Citation: Radwan N.A. (2012) Phylogenetic Analysis of Sphaerirostris picae (Acanthocephala: Centrorhynchidae) Based on Large and Small Subunit Ribosomal DNA Gene. International Journal of Parasitology Research, ISSN: 0975-3702 \& E-ISSN: 0975-9182, Volume 4, Issue 2, pp.-106-110.

Copyright: Copyright@2012 Radwan N.A. This is an open-access article distributed under the terms of the Creative Commons Attribution License, which permits unrestricted use, distribution and reproduction in any medium, provided the original author and source are credited.

\section{Introduction}

Acanthocephalans have been related to Rotifera, Nematoda, Nematomorpha and Gastrotricha [1]. Most phylogenetic analyses of phylum Acanthocephala, based on structural and molecular data, have focused on its relationships to other invertebrate phyla, however studies deal with the inter-relations between different Acanthocephala families and species with uncertain taxonomy are still out of focus.

Verweyen, et al. [2] reported that the first molecular phylogenetic analyses of Acanthocephala made by Garey, et al. [3] confirmed the major taxonomic grouping of the traditional classifications. In this grouping, Palaeacanthocephala is placed close to the Eoacanthocephala, with the Archiacanthocephala being the most basal taxon. According to Herlyn, et al. [4], the monophyly of the Palaeacanthocephala is still a matter of debate. Consequently, the assumed phylogeny of taxa within the Acanthocephala varies, placing either archiacanthocephalans $[1,5]$ or palaeacanthocephalans [6] at the base of the taxon.

Molecular data using 18S and/or 28S DNA gene sequences of family Centrorhynchidae are very limited and has indicated that the classification based on the structure of the proboscis and shape and number of its hooks is not consistent with phylogenetic relationships [3].

Amin, et al. [7] reported that, since the erection of Sphaerirostris (family Centrorhynchidae) as a subgenus of Centrorhynchus Lühe, 1911 [8], its taxonomy has been in a state of confusion and largely dependent on the use of proboscis armature, especially the number of proboscis hooks rows. This character has proven to be extremely variable through the genus, so a good number of synonymies were made. The authors accelerated that this genus is in need to a serious taxonomic revision that will be enhanced by different types of analyses based on the molecular criteria.

The purpose of the present study was to add new $18 \mathrm{~S}$ and $28 \mathrm{~S}$ DNA gene sequences data to $S$. picae as a member of the family Centrorhynchidae (Paleacanthocephala). Such data may help in understanding and defining the taxonomic placement of genus Sphaerirostris and providing a better resolution inside the Palaeacanthocephala. The phylogenetic relationships of $S$. picae were examined with 21 acanthocephalan species belonging to 9 related families that all are belongings to the class Palaeacanthocephala, 
as inferred from partial $18 S$ and $28 S$ DNA sequences. The study used an algorithm ClustalW2 for designing degenerate primers which are of particular value in amplifying homologous genes from different organisms.

\section{Materials and Methods}

\section{Specimen and DNA Isolation}

S. picae was collected from the small intestine of the Hooded crow Corvus corone cornix, Linnaeus 1758 , which is a common resident inhibiting cultivated land and wooded terrain in Nile Delta and valley in Egypt. For identification, worms were preserved in $70 \%$ ethanol, stained with Mayer's carmine, mounted in Canada balsam [9] and identified according to Dimitrova, et al. [10,11]. Specimens were stored at $-20^{\circ} \mathrm{C}$ until nucleic acid was extracted. DNA extraction followed Chloroform-Isoamyl alcohol method [12]. Three replica each of one worm were homogenized on ice in TE buffer (10 $\mathrm{mM}$ Tris-HCl, pH 7.5, $10 \mathrm{mM} \mathrm{NaCl}, 1 \mathrm{mM}$ EDTA) and digested by adding $400 \mu \mathrm{l}$ of TE buffer, $40 \mu \mathrm{l} 10 \%$ sodium dodecyl sulphate (SDS) and $10 \mu \mathrm{l}$ of $20 \mathrm{mg} / \mathrm{ml}$ protienase $\mathrm{K}$, then incubated in $55^{\circ} \mathrm{C}$ overnight. The supernatant was extracted twice with buffered phenol (pH 8.0) and once with chloroform/isoamyl alcohol (24:1). The aqueous layer $(\sim 400 \mu \mathrm{l})$ was collected and $16 \mu \mathrm{l}$ of $5 \mathrm{M} \mathrm{NaCl}$ and $420 \mu$ ice cold isopropanaol were added. The sample was cooled in the refrigerator at $-20^{\circ} \mathrm{C}$ for $10 \mathrm{~min}$ and centrifuged for $5 \mathrm{~min}$ at $15,000 \mathrm{rpm}$. The supernatant was poured off and after complete drying of the pellet, $50 \mu$ of the TE buffer was added and left for 30 min to complete dissolving. The sample was stored at $-20^{\circ} \mathrm{C}$ till use.

\section{Designing the Degenerate Primers of 28S DNA Gene}

The DNA sequences of $28 S$ DNA gene of 23 species accession numbers from $A B 500157.1$ to $A B 500179.1$ were retrieved from the sequence database of NCBI. FASTA file format of the previous sequences was used in the algorithm type of the Blast (Basic local alignment search tool). Expected values (E-values) was calculated to infer homology and distance of similarity between the sequences [13].

The mealign module implentend in the DNAStar Lasergene V7 used the Clustal $W_{2}$ algorithm for alignment collected sequences and produced the conserved blocks, which were used to design the degeneracy primers. All primer characteristics were adjusted. Primer Blast tool [14] was used to detect the homology between the designed primers and targeted templates in the GenBank database (http://www.ncbi.nlm.nih.gov/tools/primer-blast), the position of degeneracy nucleotides, and the uniqueness for the forward and reverse primers.

The PCR insilico module (Ruslan- Kalendar version 4.0.8 university of Helsinki, Finland) was used to produce all the details of the PCR program such as the optimum temperature for the forward and reverse primer, the predict PCR product, and the positions of primers on the template sequences.

\section{DNA Amplification and Sequencing}

Two regions of nuclear ribosomal DNA were amplified using polymerase chain reaction (PCR). The first is the 18S DNA using the primers: forward.5' GGGCCGTAGACGACCAAGTGTT -3' and reverse. 5'GGAAAGCGCTCGCCAAGTTATT 3' [2].

The second is 28S DNA gene using degenerate designed primers: forward 5'GTAAIG CGGCGAGTGAACTGGGAAGITA -3 ' and reserve 5'TAICACACTCGGACTAGAA AIC C AIC CA 3'.

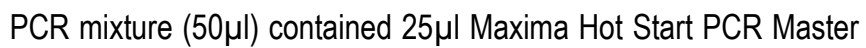
Mix (Fermentas), $1 \mu l$ final concentration of each primer, $17 \mu$ nuclease-free and $6 \mu$ l of template DNA solution. PCR cycling parameter for $18 \mathrm{~S}$ DNA gene included initial denaturation period at $95^{\circ} \mathrm{C}$ for $10 \mathrm{~min}$, annealing at $58^{\circ} \mathrm{C}$ for $1 \mathrm{~min}$ and extension at $72^{\circ} \mathrm{C}$ for 45 seconds followed by another 35 cycles at the same denaturation, annealing and extension temperatures and finished with a $10 \mathrm{~min}$ final extension at $72^{\circ} \mathrm{C}$ (after the modification of Garey, et al. [2]). A negative control (no template) was also performed for every PCR run to determine any potential contamination of the PCR products.

PCR products were evaluated by electrophoresis of $4 \mu \mathrm{I}$ PCR mixture through $1 \%$ agarose gel against I Kb ladder (Fementas), and cleaned up using Gene JET TM PCR purification Kit (fermentas) and the purified DNA was stored at $-20^{\circ} \mathrm{C}$. $2 \mu \mathrm{l}$ of PCR product was sequenced using an $A B I$ big dye terminator kit following the instructions of GATC German company facility and an ABI 3730xI DNA sequencer .

\section{Phylogenetic Analysis}

In addition to the $18 \mathrm{~S}$ and $28 \mathrm{~S}$ DNA gene sequences generated in this study, additional 21 sequences for $18 \mathrm{~S}$ DNA and 16 for $28 \mathrm{~S}$ DNA genes of other Paleacanthocephalans and one out group were obtained from the GenBank [Table-1]. The ClustalW $W_{2}$ algorithm was used to visualize the consensus sequences and the dendogram. The dendograms were built depending on the molecular based evolution set by Pearson and Lipman [15]. The matrix methods UPGMA (Unweighted-Pair-Group Methods with Arithmetic Mean) was used to present the dendrograms and the relation between homologous sequences based on the produced multiple sequence alignment [16].

\section{Results \\ DNA Sequencing and Data Set}

The sequence obtained for $18 \mathrm{~S}$ DNA is a 385 nucleotides long including primers with 59\% GC content [Fig-1], while 28SDNA sequence is a 282 nucleotide long, including primers with $58 \%$ GC content [Fig-2]. The $18 \mathrm{~S}$ and $28 \mathrm{~S}$ DNA sequences for S. picae are in the process of publication in the nucleotide data set in GenBank (NCBI). The homologous sequences for the two generated genes were retrieved from the GenBank and processed all together by mealign tool of DNAStar Lasergene V7 to produce the multiple sequence alignment. Highly conserved blocks were detected, the best position of consensus sequence was assigned.

\section{Phylogenetic Analysis}

Molecular analyses of both $18 \mathrm{~S}$ and 28S DNA using matrix unweighted pair-group method with arithmetic mean (UPGMA) revealed the degree of genetic similarity between $S$. picae and all retrieved species [Fig-2], [Fig-3] using full optimization and 1000 bootstrap replicates. 
Table 1- Species related to class Palaeacanthocephala and represented in the phylogenetic analyses with Gene bank accession numbers.

\begin{tabular}{|c|c|c|c|c|}
\hline Order & Family & Species & 18rDNA & 28rDNA \\
\hline \multirow[t]{2}{*}{ Polymorphida } & Centrorhynchidae & Centrorhynchus sp. & AY830155 & AY829104 \\
\hline & & Sphaerirostris picae & Present study & Present study \\
\hline \multirow{9}{*}{ Polymorphida } & Polymorphidae & Polymorphus sp & AF001838 & - \\
\hline & & Profilicollis botulus & EU267805 & EU267818 \\
\hline & & Pseudocorynosoma constrictum & EU267800 & EU267812 \\
\hline & & Corynosoma strumosum & EU267804 & EU267816 \\
\hline & & Andracantha gravida & EU267802 & EU267814 \\
\hline & & Southwellina hispida & EU267807 & - \\
\hline & & Arhythmorhynchus brevis & AF064812 & - \\
\hline & & Ibirhynchus dimorpha & GQ981436 & GQ981437 \\
\hline & & Hexaglandula corynosoma & EU267808 & EU267817 \\
\hline Polymorphida & Plagiorhynchidae & Plagiorhynchus cylindraceus & AF001839 & AY829102 \\
\hline \multirow[t]{2}{*}{ Echinorhynchida } & Rhadinorhynchidae & Gorgorhynchoides bullocki & AY830154 & AY829103 \\
\hline & & Rhadinorhynchus sp & AY062433 & AY829099 \\
\hline \multirow[t]{2}{*}{ Echinorhynchida } & Transvenidae & Pararhadinorhynchus sp & HM545903 & - \\
\hline & & Transvena annulospinosa & AY830153 & AY829098 \\
\hline Echinorhynchida & Cavisomidae & Filisoma bucerium & AF064814 & AY829110 \\
\hline Echinorhynchida & Arhythmacanthidae & Acanthocephaloides propinquus & AY830149 & AY829100 \\
\hline Echinorhynchida & Pomphorhynchidae & Pomphorhynchus laevis & AY218124 & - \\
\hline \multirow[t]{2}{*}{ Echinorhynchida } & Echinorhynchidae & Echinorhynchus gadi & AY218123 & AY218146 \\
\hline & & Acanthocephalus dirus & AY830151 & AY829106 \\
\hline Echinorhynchida & Unclassified Echinorhynchida & Echinorhynchida sp. & EU732662 & - \\
\hline Out group & Trhypochthoniidae (Arthropoda) & Trhypochthonius tectorum & HQ711371 & - \\
\hline
\end{tabular}

\begin{tabular}{|lllll|}
\hline 1 & TTATGNTTGT & CTCTTGTGAT & GCGCTTCATT & GTGTGTCTCG \\
41 & GTGAAGAGCC & ACTGTTCACT & TTGAAAAACT & CAGTGTGCTC \\
81 & AATGCAGGCT & AACTGCTCGA & ATTACGCTGC & ATGGGATGAT \\
121 & GAAATGGGGT & CTCCGCTCCG & TTTCGTTGGT & TTACNAAAGC \\
161 & AAAGAACATG & ATTAATCGGG & ACAGACGGGG & CATTCGTAT \\
201 & TGCGGTGCTA & AAATTGAAAT & TCTGTGACCA & TCGCAAAACA \\
241 & AACAACTGCA & AAAGCATTTG & CCAAAAATGT & TTTCTTTAAT \\
281 & CACAAACAAA & AGTTAAAGGA & TCAAAAACAA & TTAAATACCG \\
321 & TCCTATTTCT & AACGGTAAAC & TGTGCCGGCC & AGGAATTCCC \\
361 & CAACGCAATA & ACTTGGCAAN & CCCTT & \\
\hline
\end{tabular}

Fig. 1- Nucleotides sequence of 361 bp fragments of 18 S DNA gene of Sphaerirostris picae.

\begin{tabular}{|lllll|}
\hline 1 & CCACGTTTAT & TCATGCGGTG & GTTAGTATGA & GTGATAATGC \\
41 & GTGCTTGTCC & AGGTGTGCTG & CTTCTCCAGC & TATCCGCATT \\
81 & TGTAAGTTCG & CTTGACTGTA & GTAACTTTGA & AAGATGGTGC \\
121 & GAGACCTGCA & TGAGTGGGTG & GTGGTTGCCG & ATATTGGTT \\
161 & CTGCTTCAGA & GTCGAGTTGC & CTGGGAACGC & ATCTCAAAGT \\
201 & CGTTGGTAAA & CCTCATCTAA & AGCTAAATAT & GACTTCGAGA \\
241 & CCGATACCGA & ACAACTACCG & TGAGGAAAAT & TTGCCAATAA \\
281 & CT & & & \\
\hline
\end{tabular}

Fig. 2- Nucleotides sequence of 281 bp fragments of $28 S$ DNA gene of Sphaerirostris picae.

For 18S DNA gene, the analysis yielded a single tree [Fig-3], [Fig4], where Palaeacanthocephalans show high diversity. The tree represents order Echinorhynchida and order Polymorphida in a paraphyletic arrangement. The three major clades of order Echinorhynchida lack genus Gorgorhynchoides, which is allocated it in the polymorphid cluster. The first clade of Echinorhynchid carries both Pomphorhynchus (family Pomphorhynchidae) and Echinorhynchus (family Echinorhynchidae) with a genetic similarity 95.7\%. Acanthocephalus (family Echinorhynchidae) and Filisoma (family Cavisomidae) have high genetic similarity $96.8 \%$, the clade that carries both generasisters to that of Echinorhynchida (family Echinorhynchidae) and Acanthocephaloides (family Arhythmacanthidae). The clade carries Transvena and Pararhadinorhynchus (family Transvenidae) and Rhadinorhynchus (family Rhadinorhynchidae) appears separate from the other 2 major clades.

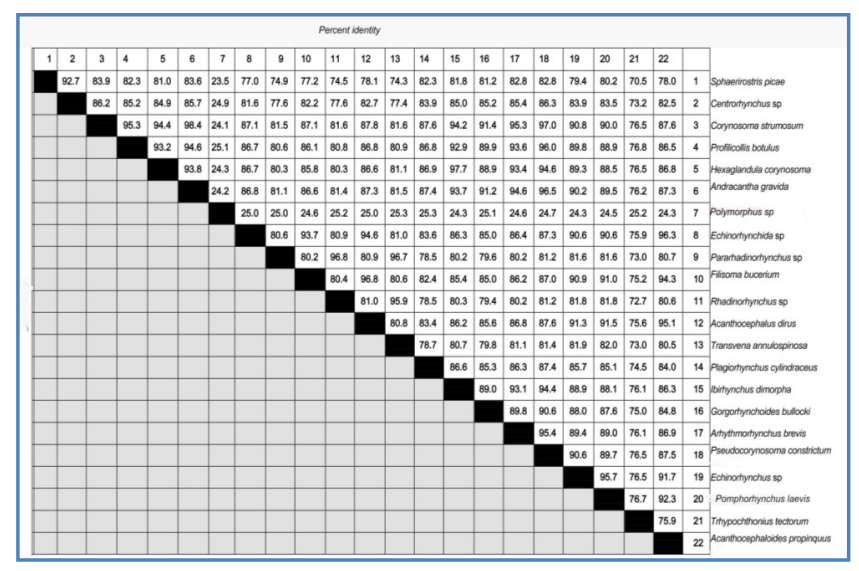

Fig. 3- Percent identity based on 18S DNA gene between Sphaerirostris picae and twenty two species belong to orders Echinorhynchida and Polymorphida (Palaeacanthocephala) retrieved from GenBank.

The cluster of Polymorphida includes one echinorhynchid namely Gorgorhynchoides. The most basal genus in the polymorphid clade is Plagiorhynchus, followed by the clade of both Sphaerirostris and Centrorhynchus (family Centrorhynchidae) with a genetic similarity 92.7\%. Plagiorhynchus and Sphaerirostris have $82.3 \%$ similarity distance. Two clades in the cluster of family Polymorphidae carry taxa with high genetic similarity; the first carries Ibirhynchus with 
Hexaglandula (97.7\%) and the second includes Andracantha with Corynosoma ( $98.4 \%)$.

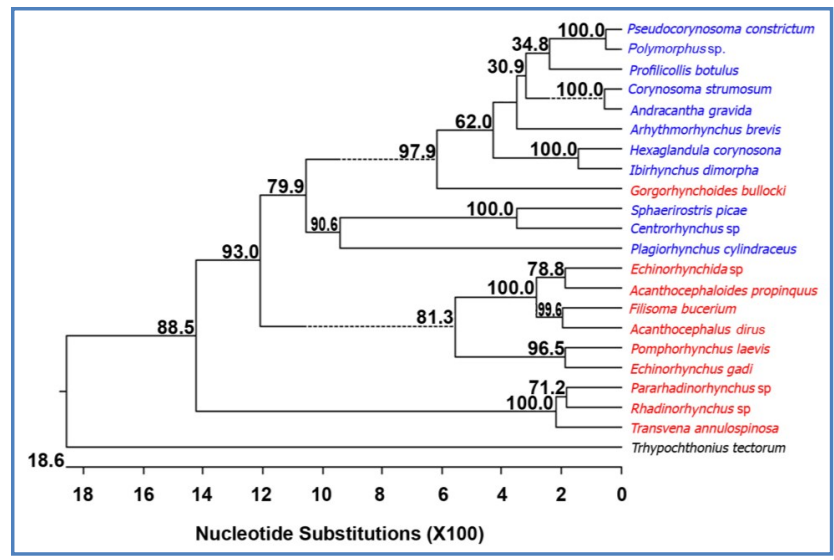

Fig. 4- Percent identity based on 28S DNA gene between Sphaerirostris picae and sixteen species belong to orders Echinorhynchida and Polymorphida (Palaeacanthocephala) retrieved from GenBank.

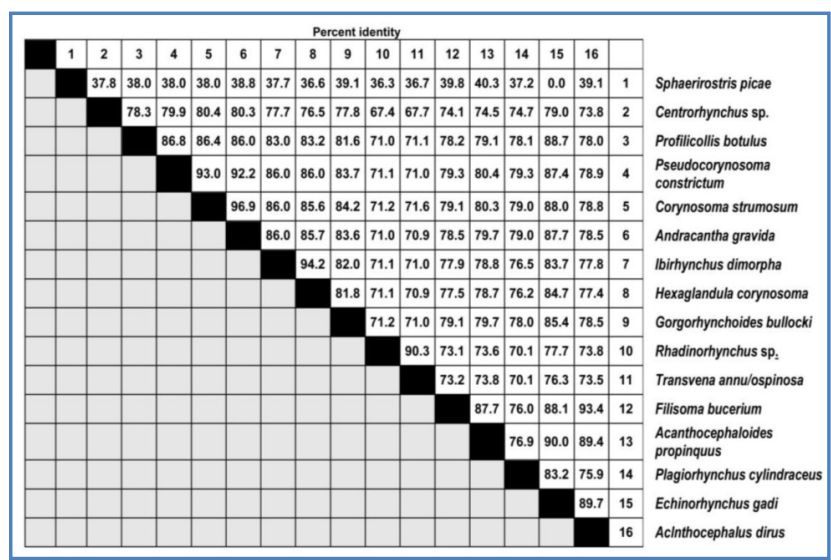

Fig. 5- Phylogntic dendrogram for Paleacanthocephala relationships based on the 18S DNA data set. Arthropoda is used as outgroup. The tree illustrates that the order Echinorhynchida (red) and Polymorphida (blue) have a paraphyletic arrangement. The branch length scale is the number of substitutions per site.

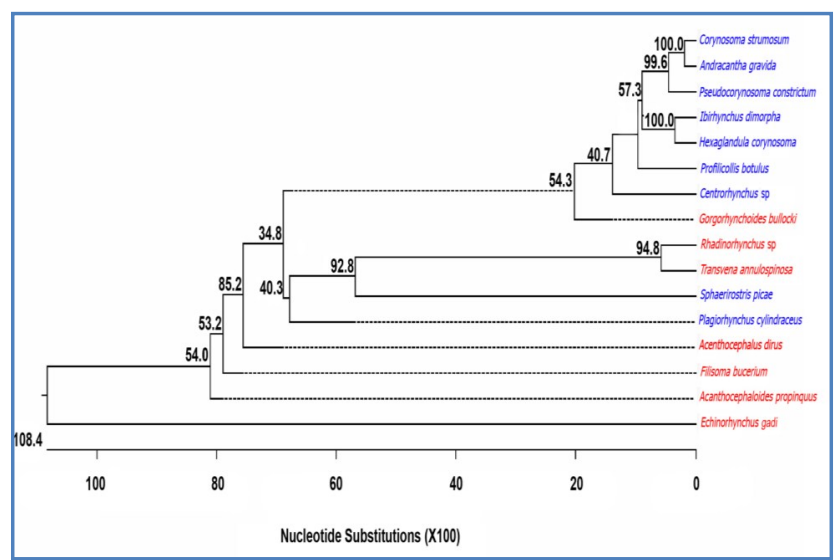

Fig. 6- Phylogntic dendrogram for Paleacanthocephala relationships based on the 28S DNA data set. The tree confirms the paraphyletic arrangement of order Echinorhynchida (red) and Polymorphida (blue). The branch length scale is the number of substitutions per site.
Analysis based on 28S DNA gene [Fig-5], [Fig-6] represents two major clades of Palaeacanthocephala. The first is of Echinorhynchida, which lacks the two closely related genera; Transvena and Rhadinorhynchus (90.3\%genetic similarity), in addition to Gorgorhynchoides which are all allocated in the polymorphid clade. The clade of Transvena and Rhadinorhynchus formed a sister group to Sphaerirostris (family Centrorhynchidae). Echinorhynchus is the most basal genus in the echinorhynchids. It has $89.7 \%$ genetic similarity with Acanthocephalus which is related to the same family (Echinorhynchidae), being relatively more close to Acanthocephaloids (Arhythmacanthidae) ( $90 \%$ genetic similarity).

Depending on 18S DNA gene analysis, S. picae has high genetic similarity ratio (92.7\%) with Centrorhynchus sp (Centrorhynchidae) [Fig-3], [Fig-4], while in that of 28S DNA gene [Fig-5], [Fig-6], both species are separated by a Echinorhynichids clade encloses Transvena, Rhadinorhynchus and Gorgorhynchoides.

\section{Discussion}

The relationship of the Acanthocephala to other invertebrate phyla has been estimated recently by analysis of structural and molecular data. The first molecular phylogenetic analyses within Acanthocephala [2] confirmed the major taxonomic grouping of the traditional classifications. In that analysis, Palaeacanthocephala was placed close to the Eoacanthocephala, while Polyacanthocephalans appeared sister to the Eoacanthocephalans with the Archiacanthocephala being the most basal taxon [3]. Previous studies of acanthocephalans combined data sets of both, 18S and 28S DNA $[2,17]$. The present study data set adds to the most recent analyses of Palaeacanthocephala relationships by García-Varela and Nadler [17], Garey, et al. [2] and Verweyen, et al. [3].

Palaeacanthocephala include two orders; Echinorhynchida and Polymorphida. According to Verweyen, et al. [3], these species rich taxa include 83 genera and 594 species of Acanthocephalans. Both orders demonstrate high morphological diversity, which may explain why traditional identification keys have distinguished taxa according to their final hosts. Based on traditional classification, Echinorhynchida is divided into 10 families and 339 valid species, while Polymorphida includes only three families and a total of 255 valid species [3].

The present study analyzed the relationships between the three polymorphids families and six of the echinorhynchids families using both 18S and 28S DNA gene analytical methods which revealed the paraphyletic assembly of Palaeacanthocephala. This finding is incorporated by the previous analysis of Herlyn, et al. [4] and Verweyen, et al. [3], however both studies depended only on the analysis of 18S DNA gene. Otherwise, phylogenetic analysis based on morphological and ecological characters of Palaeacanthocephala $[5,18]$ revealed the monophyletic form of this class.

The present 18S DNA gene analysis indicates that the family Rhadinorhynchidae (Echinorhynchida) is paraphyletic, where the analysis allocates Gorgorhynchoides bullocki in the Polymorphida cluster. This replacement is confirmed by the present analysis based on 28S DNA gene, where Rhadinorhynchus sp which belongs to the same family (Rhadinorhynchidae), presents together with Gorgorhynchoides bullocki in the same position. This finding was in agreement with the previous reports of Verweyen, et al. [3]_ Herlyn, 
et al. [6] and. García-Varela and Nadler [17]. In addition, Shih, et al. [19] traditionally classified Rhadinorhynchus pristis as a member of order Polymorphida. It is worth mentioning here that Gorgorhynchoides has trunk hooks on its praesoma (only some echinorhynchid acanthocephalans have irregularly arranged hooks on the trunk) while the regular distribution of hooks on the trunk is one of the most common features within the polymorphids.

Based on 18S and 28S DNA gene analysis, the polymorphid; Plagoirhynchus cyndraecus is placed between Polymorphid and Echinorhynchid clades. Morphologically, this species has some Echinorhynchid characters, where the cylindrical trunk has anterior hooks and the males have six cement glands [3].

An interesting finding in the present study, revealed by 18S DNA gene analysis, is the relatively close relation of Sphaerirostris picae (family Centrorhynchidae) with Plagoirhynchus cylindraceus (Plagiorhynchidae) when compared with the relation of $S$. picae with the other species. Morphologically, the later species is characterized by cylindrical fusiform aspinose trunk, slender lemnisci, and 6 elongate tubular cement glands in the males. Sphaerirostris has the same characters except only 4 cement glands. Otherwise, Amin, et al. [7] reported the presence receptacle process at the anterior end of the proboscis receptacle of $S$. picae, this trait distinguishes this species from all other species of its genus. A similar structure was reported previously in the proboscis of Plagiorhynchus digiticephalus (Plagiorhynchidae) [20], These facts might introduce a justification of the close relation of both genera.

The present analysis of 18S DNA gene shows high similarity ratio $(92.7 \%)$ between Sphaerirostris and Centrorhynchus. Dollfus and Golvan [21] listed both Centrorhynchus teres Westrumb, 1981 and Centrorhynchus (Sphaerirostris) picae Rudolphi,1819 as valid species. The present analysis of 28S DNA gene separates Sphaerirostris from Centrorhynchus by two clades represents three Echinorhynchid species. Morphologically, Golvan [8] erected Sphaerirostris Rudolphi, 1819 as subgenus of Centrorhynchus Lühe,1911, later he [22] listed 26 species of Sphaerirostris by reversing the synonymies, where the differentiation was based on the proboscis armature [7]. Relations between the two main genera of Family Centrorhynchidae need further analysis based on both morphological and molecular data.

To the best of our knowledge, no data set are available for either $18 S$ or 28S DNA genes of Sphaerirostris, the present study is the first to add gene sequences to this genus. As the taxonomy of Sphaerirostris was largely based on the proboscis armature, and this character has proven to be extremely variable [7], further comprehensive studies should be done for other species of this genus based on molecular analysis to solve their taxonomic overlapping.

\section{Acknowledgement}

The author would like to thank Dr. Abdallah A. Sharaf lecturer in Genetic Engineering Unit, Faculty of Agriculture, University of Ain Shams for his critical help the molecular work.

\section{References}

[1] García-Varela M., Cummings M.P., Perez-Ponce de León G., Gardner S.L., Lacletteam J.P. (2000) Journal of Molecular Evolution., 50, 532-540.
[2] Garey J.R., Near T.J., Nonnemacher M.R., Nadler S.A. (1996) Molecular Phylogenetics and Evolution, 43, 287-292.

[3] Verweyen L., Klimpel S., Palm H.W. (2011) PLoS One, 6(12), e28285.

[4] Herlyn H., Piskurek O., Schmitz J., Ehlers U., Zischlera H. (2003) Molecular Phylogenetics and Evolution, 26,155-164.

[5] Near T.J., Garey J.R., Nadler S.A. (1998) Molecular Phylogenetics and Evolution, 10, 287-298.

[6] Herlyn H., Martini N. and Ehlers U. (2001) Systematic Parasitology, 50, 105-116.

[7] Amin O.M., Heckmann R.A., Halajan A., Eslami A. (2010) Journal of Parasitology, 96(3), 561-568.

[8] Golvan Y. (1956) Bulltin de l'institute francais d'afrique Noire (Ser. A)., 18, 732-785.

[9] Amin O.M. (1998) NOAA Technical Report NMFS, 135.

[10]Dimitrova Z. and Genov T. (1992) Folia-Parasitologica, 39(3), 235-247.

[11]Dimitrova Z., Georgiev B., Genov T. (2000) Acta. Zoologica. Bulgerica., 52(3), 3-32.

[12]Benesh D.P., Hasu T., Soumalainen L.R., Valtonen E.T., Tirola M. (2006) International Journal of Parasitology, 36(2), 247-254.

[13]Ezz M.A., Soliman M.H., Gamal El-Din A.Y., Abdelsalam A.Z.E. (2010) Journal of Life Science, 4(6), 1934-7391.

[14]Rozen S., Skaletsky H. (2000) Methods. Molecular Biology. 132, 365-386.

[15]Pearson W.R., Lipman D.J. (1988) Proceeding of Natl. Academic Science, USA., 85(8), 2444-2448.

[16]Sokal R.R., Michener C.D. (1958) University of Kansas Science Bulletin, 28, 1409-1438.

[17]García-Varela M., Nadler S. (2005) Journal of Parasitology, 91, 1401-1409.

[18]Monks S. (2001) Systematic Parasitology, 48, 81-116.

[19]Shih H.H., Chen H.Y., Lee C.Y. (2010) Taiwania, 55(2), 123127.

[20]Amin O.M., Heckmann R.A., Ha N.V. (2008) Acta. Parasitologica, 56(1), 67-77.

[21]Dollfus R.P., Golvan Y. (1957) Note Rectificative Bulletin IFAN, Ser. A., 19, 412- 416.

[22] Golvan Y. (1994) Res. Parasitology, 54, 135-205. 